\title{
On lenses and blind spots in qualitative exercise and environment research: A Response to Stephanie Coen
}

\begin{abstract}
Qualitative research focused on how people experience the social and material environments in which they exercise has the potential to inform public health agendas in all sorts of ways. This commentary takes up the claim made by Stephanie Coen that such research should begin with an 'equity lens' and place a greater emphasis on 'critique' than we did in the 'Exercise and Environment' special issue to which she responds. At its best qualitative research reveals new ways of thinking about the social and material contexts at hand. As such, it has the potential to highlight important dimensions of the lived experience of popular fitness practices that may have hitherto been relatively overlooked. Always starting with the overt aim of applying an 'equity lens' truncates the possibility of discovering such dimensions. Furthermore, being too wedded to an overtly critical stance may end up hindering, rather than encouraging, the most positive dialogue between those studying the cotemporary exercise experience and those involved in public health.
\end{abstract}

\section{Highlights}

- Qualitative research can usefully illuminate the cotemporary relationship between exercise and environment

- A greater dialogue between relevant researchers and those in public health could bring tremendous benefits

- An overt focus on 'equity' and 'critique' is one of many possible ways of developing this dialogue

\section{Key words}

Qualitative methods, physical fitness, exercise, environment, public health, dialogue

\section{Introduction}

That physical activity is beneficial to human health is undisputed. Physical activity is related to lower mortality risks for CHD (Bull, 2004), cancer (Colditz et al.,1997; Tehard et al., 2006), and type II diabetes (Tuomilehto et al., 2001). It slows the musculoskeletal health decline associated with ageing (Huang et al. 1998). Physical activity and physical exercise have also been shown to have beneficial impacts on mental health and general wellbeing (Glenister, 1996; Hassmen et al., 2000). Despite these benefits, significant proportions of the adult populations in most wealthy countries do not reach internationally accepted recommended guideline levels of physical activity. This is the case whether 
people are rich or poor, men or women, and is seen across all age groups beyond childhood and adolescence (Cavill et al., 2006; USCDC, 2017; Hallal, 2012). Certainly we can see significant variation across different demographic groups, between women and men, and between (and within) countries (Colley, 2011; Tucker, 2011; Ng, 2012; Andersen et al., 2016). Nonetheless, this 'pandemic of inactivity' as the recent Lancet report on physical activity characterised it (Kohl et al., 2012), is a phenomenon with a very broad demographic reach. Meanwhile, at the same time and in stark contrast to the population level picture, in many of these same countries we have seen a blooming popular interest in a whole range of physical fitness practices. It was with this in mind that the recent Health and Place special issue on 'Exercise and Environment' that we edited explored some of the ways in which a broad, and growing, volume of qualitative research on how everyday people are now exercising 'in the wild' might be more fully brought into conversation with those in public health (Hitchings and Latham, 2017). The central premise in doing so was that helping those involved in public health-be they urban planners, medical professionals, local authorities, politicians, or whosoever-to better engage with and amplify these popular physical fitness practices could bring tremendous benefits.

\section{The argument}

This argument rests on two assumptions. The first is that it is worthwhile having a dialogue with those involved in public health initiatives — whether that be those engaged in setting agendas, or those seeking to implement such agendas through concrete interventions-about the detail of the contemporary exercise experience. The second is that qualitative research on how people exercise has the potential to reveal aspects of this experience that other approaches may otherwise miss. The strength of qualitative research is that—done well—it provides detailed, contextually rich, insights into how particular people engage in the physical fitness activities they do. It also brings into view a whole range of elements and relationships associated with the social and material contexts being studied that might not be otherwise apparent. This is significant because the literature on physical fitness and public health can often tend to concentrate on the social barriers to exercise or on more general motivations for exercising. Yet, there is much to be gained from thinking about the variegated experiences of those who are already exercising in different ways and different environments. Examples range from the fact that people like exercising around others, even when ostensibly alone (Krenichyn 2004); to the ways in which certain exercise machines help hold motivation in place (Hitchings and Latham 2016); to how exactly different environments are enfolded into the mental pleasures of exercising (Lorimer 2012), to name but a few.

In her response to our special issue, Coen considers how this line of research should proceed. In this respect, she makes links to a tradition of qualitative health geography work (see Fenton and Baxter, 2016, for recent examples) which is valuable, but with which we did not engage greatly because our 
focus was squarely on thinking afresh about the contemporary exercise experience and the environments associated with it. Our understanding of her core argument is that we should replace our comparatively open approach with 'an equity lens' (p. 1) because, without the critical stance that is often linked to this lens, research on exercise and environment 'does not go far enough' (p. 1). In this short commentary, we take the opportunity to clarify our position on these matters. We think that adopting such a lens is not the only way to go. Indeed, to assume that it is may be unhelpfully limiting.

\section{The need for an 'equity lens'}

The way of characterizing the role of qualitative research in studying exercise and environment that we developed in the Special Issue is certainly not universally shared. There are many who, like Coen, locate qualitative approaches within a more overtly critical tradition of social science and social commentary. In such work, qualitative research is defined in opposition to conventional, mainstream, instrumentally oriented social science. This is the tradition that Coen clearly associates herself with in her response. Without an explicit focus on equity, public health interventions will, as she puts it, necessarily 'exacerbate health inequalities' (p. 2). More-than-that, she argues an 'equity lens' is essential for studying exercise practices and public health research as without it research is insufficiently critical. In other words, if we fail to pick away at the hidden networks of power that are taken to structure all social action, we are not doing our job properly. Understood in this way, the role of the good qualitative researcher is not just to describe and understand relevant social sites and practices, but also to develop a wider critique of the inequities that are presumed to run through them.

Our view is that the 'equity lens', though not without its merits, is but one possibility. And it is one that we worry can be limiting in at least two ways. This is firstly in terms of what it means for how our studies are designed. Coen states that "physical activity participation is, quite simply, inequitable" (p. 2) and it certainly is the case that practices of physical fitness tend to vary systematically across a range of social categories. Yet, given that physical activity levels are deficient all across the demographic spectrum in most affluent countries, it is not at all clear to us why researchers should only be focusing on the most under privileged (Cavill et al. 2006; Colley 2011; Tucker 2011; Hallal et al. 2012; Ng 2012). Nor is it so clear to us that experiences of exercising will necessarily be radically different across different social groups. We worry about the tendency to put predefined group identities centre stage in understanding people's relationship with their exercise environments when a whole range of other factors might be equally worthy of attention in understanding how certain practices emerge and become entrenched. By jumping the gun through an a priori focus on certain groups who seemingly need particular help and attention, we, for example, downplay broader societal dynamics that may be all the more powerful by virtue of the fact that all potential exercisers are subject to them. 
The argument we made in the 'Exercise and Environment' Special Issue is that qualitative explorations of how and where exercise practices are undertaken can help inform public health work precisely because they tell us things that we do not yet know. This takes us to our second response to the suggested importance of the 'equity lens' since to define our objective too fully in advance runs against all that is most attractive to us about a qualitative approach. Adopting a qualitative research strategy opens up an ability to reveal new ways of thinking about the context at hand. Rather than focusing on barriers to exercise, or assuming that popular fitness practices are defined by the disciplining webs of neoliberalism, or commodification, or whatever other pernicious force that seemingly surrounds them, this method allows a sense of what matters to emerge. And though the kinds of insights that follow from this undertaking might initially seem rather modest, for us that is precisely the point. There is much that we do not yet know about how exercise and environment can, and could, come together. And thinking about how exercise is carried out and experienced by different people in varying environments has the potential to suggest all sorts of ways of recalibrating or modifying existing public health strategies to make them more effective and inclusive. Our point here is that immediately reaching for the 'equity lens' necessarily blinds us to the very many dynamics that may emerge from our studies. And these dynamics could be even more helpful in defining the most effective ways of responding to the contexts at hand by virtue of having been derived from a less circumscribed examination of exercise and its environments.

\section{Not going 'far enough' and going too far}

This takes us to our next point, which is about the value of the researcher taking a 'critical' stance. In this respect, whilst Coen contends that we do not 'go far enough' in drawing out the equity implications of our studies, we rather think that setting out with an overtly critical agenda might itself be going too far. Again this is for at least two reasons. Firstly, it is not clear why we should expect those in public health to listen to our critiques. We imagine that many public health workers-from policy makers to those involved in implementation — are well aware of the ambiguities, limitations, compromises, and power imbalances involved in their work. They do not need this knowledge reinterpreted through the lens of critical social science. Rather they are interested how they can negotiate policy environments that are constrained and far from perfect. And if we want to engage with them, starting out with ambitions that centre on academic critique seems unwise to us.

Secondly, there are many productive things that qualitative researchers can do which are precluded by a critical stance. Qualitative researchers, for example, might offer concrete suggestions to improve public health initiatives; things like understanding better how some people get pulled into exercise practices, 
and others not. Some of this will certainly involve issues to do with social equity. So, for example Coen (p. 4) highlights how initiatives that encourage doctors to prescribe exercise as medicine often fail because patients find gyms intimidating. To help address these issues, qualitative researchers could work with gyms and those issuing exercise prescriptions to understand what elements help beginners to develop a positive exercise routine. They could explore how exactly such patients interact with exercise machines, staff, and other exercisers. The work of Sassatelli (2010) and Crossley (2006), for example, provide a range of pointers for this. Qualitative researchers might also explore what other contexts those with similar characteristics to those being targeted are already exercising in and how their peers might be encouraged to join them there (see for example Mehlman Petrzela, 2016; Phoenix and Orr 2014). The point here is that the aim is not, by definition, about critique. Instead it is about finding useful ways of conversing and collaborating across disciplinary and organisational boundaries.

Productive exchange between academic researchers and those involved in policy is hard (Cairney and Oliver 2017). Part of the answer to these problems is about writing accessibly so those outside our specialisms can understand our findings. Another is about being attuned to the issues that face those with whom we hope to engage. Either way, starting out with the assumption that they are to be criticised, which is what those who take the 'critical' stance do often end up doing, seems unwise to us. The 'critical stance' is a frustrating commonplace in academic work because it immediately positions the researcher as someone who stands above the detail of everyday practice to discern deeper structures that should be challenged. And, whilst we would certainly argue for a questioning approach to how relevant issues are framed by various policies and parties, in this sense we rather think that starting with the critical stance is itself going too far. We worry that such a stance stops us from engaging with the detail. It places us apart from, rather than alongside, those who we may want to work with and influence. And, in this way, we think the results are further unhelpful blind spots because of an, albeit laudable, starting ambition about reframing problems and challenging presumed injustice.

\section{Conclusion}

The 'Exercise and Environment' Special Issue that we edited drew together a range of recent qualitative studies focused on how and where popular fitness practices are undertaken. It explored a variety of popular fitness practices, from recreational running, mountain biking, and walking, to swimming, cycling, and mixed martial arts. There are many others worth exploring. And such explorations should be alive to how practices of physical exercise intersect with questions of social equity. However, one of the strengths of qualitative approaches for studying such practices is their fine-grained attention to the how and where of undertaking them. This is because, drawing on that strength has the potential to highlight important dimensions to the experience that may hitherto have gone relatively unexamined. 
And for qualitative researchers to realise this potential, various ways of conversing with those who set and implement public health agendas are required. In this respect, whist we do not want to argue against the value of the work that Coen proposes, we do want to be mindful of the blind spots that necessarily accompany the 'equity lens' and cautious about adopting certain 'critical' academic positions that are sometimes more alluring than useful.

\section{Acknowledgements}

We would like to thank Jamie Pearce for the opportunity to write this response and comments on an earlier draft.

\section{References}

Andersen, L., Mota, J., Di Pietro, L., 2016. Update on the global pandemic of physical inactivity. Lancet. $388,10051,1255-6$.

Bull, F., Armstrong, T., Dixon, T., Ham, S., Neiman, A. Pratt, M., 2004. Physical inactivity. In: M., Ezzati, A., Lopez, A., Rodgere, C., Christopher, Murray, J. eds. Comparative Quantification of Health Risks: Global and Regional Burden of Disease Attributable to Selected Major Risk Factors. World Health Organization, Geneva.

Cairney, P., Oliver, K. 2017. Evidence-based policymaking is not like evidence-based medicine, so how far should you go to bridge the divide between evidence and policy? Health Research Policy and Systems, 15, 1, 35 .

Cavill, N., Kahlmeier, S., and Racioppieds, F., 2006. Physical Activity and Health in Europe: Evidence for Action. World Health Organization, Geneva.

Coen, S. (2017) Connecting qualitative research on exercise and environment to public health agendas requires an equity lens. Health and Place. doi.org/10.1016/j.healthplace.2017.09.005

Colditz G, Cannuscio C, Frazier A. 1997. Physical activity and reduced risk of colon cancer: implications for prevention. Cancer Causes and Control, 8: 649-667. 
Colley, R., Garriguet, D., Janssen, I., Craig, C., Clarke, J., Tremblay, M., 2011. Physical activity of Canadian adults: Accelerometer results from the 2007 to 2009 Canadian Health Measures Survey. Health Reports, 22, 1, 1-8.

Crossley, N., 2006. In the gym: motives, meaning and moral career. Body Soc. 12, 23-50.

Fenton, N. and Baxter, J. 2016. Practicing qualitative methods in health geographies. Routledge, London.

Glenister, D., 1996. Exercise and mental health: a review. Journal of the Royal Society of Health.116, $7-13$.

Hallal, P., Andersen, L., Bull, F., Guthold, R., Haskell, W., Ekelund, U., Lancet Physical Activity Series Working Group, 2012. Global physical activity levels: surveillance progress, pitfalls, and prospects. Lancet 380, 247-257.

Hassmen., P, Koivula N, Uutela A., 2000. Physical exercise and psychological well-being: a population study in Finland. Preventive Medicine. 30, 17-25.

Hitchings, R., Latham, A., 2016. Indoor versus outdoor running: understanding how recreational exercise comes to inhabit environments through practitioner talk. Trans. Inst.

Br. Geogr. 41, 503-514.

Hitchings, R., \& Latham, A. 2017. Exercise and environment: New qualitative work to link popular practice and public health. Health \& Place. 46, 300-3006.

Huang, Y., Macera, C., Blair, S., Brill, P., Kohl, H., Kronenfeld, J., 1998. Physical fitness, physical activity, and functional limitation in adults aged 40 and older. Medicine and Science in Sports and Exercise , 30:1430-1435.

Kohl, H., Craig, C., Lambert, E., Inoue, S., Ramadan Alkandari, J., Leetongin, G., Kahlmeier, S., Lancet Physical Activity Series Working Group, 2012. The pandemic of physical inactivity: global action for public health. Lancet 380, 294-305.

Krenichyn, K., 2004. Women and physical activity in an urban park: enrichment and support through an ethic of care. J. Environ. Psychol. 24, 117-130. 
Lorimer, H., 2012. Surf. Slopes Performance Research. 17, 83-86

Mehlman Petrzela, N., 2016. When Wellness is a Dirty Word. Chronicle of Higher Education. May 6. Available at: http://www.chronicle.com/article/When-Wellness-Is-a-Dirty-Word/236266

Ng, S., Popkin, B., 2012. Time use and physical activity: a shift away from movement across the globe. Obes. Rev. 13, 659-680.

Phoenix, C., Orr, N., 2014. Pleasure: a forgotten dimension of physical activity in older age. Soc. Sci. Med. 115, 94-102.

Sassatelli, R., 2010. Fitness Culture: Gyms and the Commercialisation of Discipline and Fun. Palgrave Macmillan, London.

Tehard, B., Friedenreich, C., Oppert, J., Clavel-Chapelon, F., 2006. Effect of physical activity on women at increased risk of breast cancer: results from the E3N Cohort Study. Cancer Epidemiology, Biomarkers and Prevention,15, 1, 57-64.

Tuomilehto J, Lindström J, Eriksson J, Valle T, Hämäläinen H, Ilanne-Parikka P, KeinänenKiukaanniemi S, Laakso M, Louheranta A, Rastas M, Salminen V, Uusitupa, M., 2001. Finnish Diabetes Prevention Study Group. Prevention of type 2 diabetes mellitus by changes in lifestyle among subjects with impaired glucose tolerance. New England Journal of Medicine. 344, 18,1343-1350.

Tucker, J., Welk, G., Beyler, N., 2011. Physical Activity in U.S. adults compliance with the physical activity guidelines for Americans. American Journal of Preventive Medicine. 40, 4,454-461.

USCDC. 2017., Facts about physical activity. United States Centres for Disease Control, Atlanta, GA https://www.cdc.gov/physicalactivity/data/facts.htm Accessed 31 October 2017. 